ing new aspects of molecular cell biology are within the stated scope of the new journal, including cell-cell and cell-matrix adhesive mechanisms together with downstream signalling pathways as determinants of gene expression and morphogenesis, molecular mechanisms of cellular responses to cytokines and chemotactic factors, intracellular transport and cellular interactions in immune responses. With the huge popularity of these topics, there is inevitably a niche for good quality journals to relieve pressure on the principal cell-biology outlets.

Cell Adhesion and Communication seems likely to succeed in filling part of this niche along with other good secondary journals. The 29 papers in the four issues of the first volume are generally of high quality and interest and indicate a nice geographical spread of contributors, reflecting presumably the well balanced make-up of the editorial board. The quality of the illustrations is good and it is to be hoped that in time the publishers will find a way to place the (free) colour pictures in context, without segregating them at the back of each issue. The cost of the journal appears to be fluid, with the personal subscription rate rising by 50 per cent in 1993 to $\$ 135$ - a bit steep at the present slimline stage of evolution. The publishers are coy about academic and corporate institutional rates but, if reasonable, Cell Adhesion and Communication will be a valuable addition to the library shelf. $\quad \square$

R. C. Hughes is at the National Institute for Medical Research, The Ridgeway, Mill Hill, London NW7 1AA, UK.

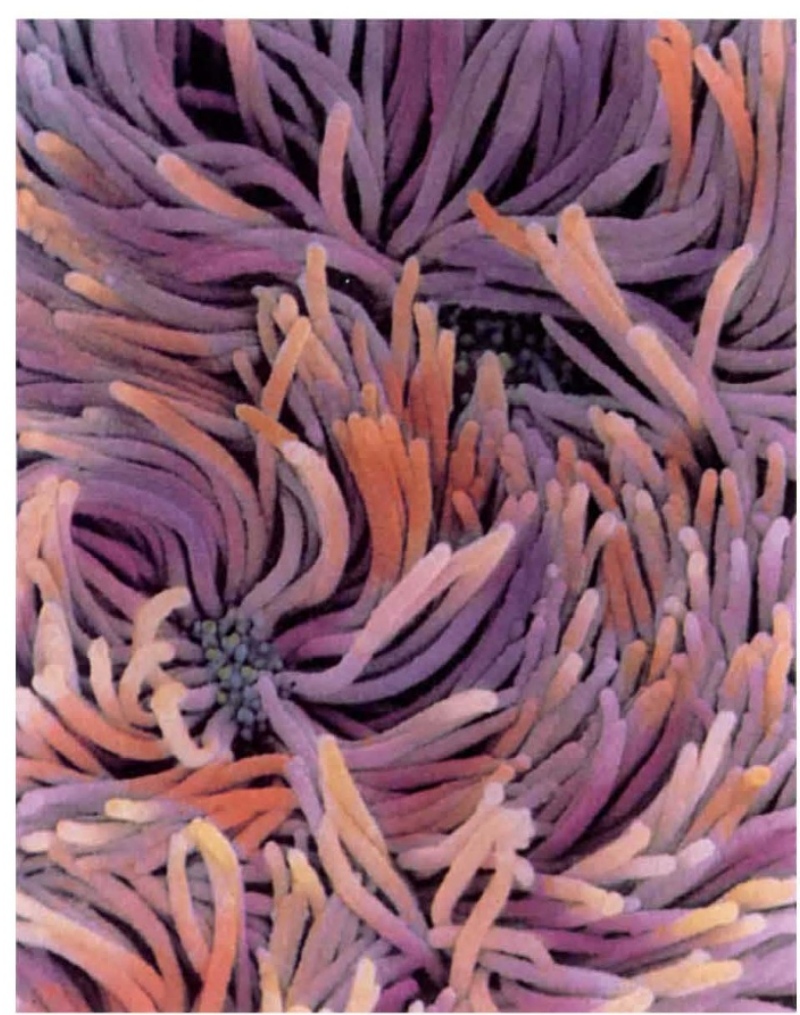

Ciliated tracheal epithelium (false-colour SEM, $x \sim 5,000$ ).

\section{Drugs, cells and mechanisms}

\section{N. G. Bowery}

Cellular Pharmacology. Editors Claude Jasmin, Kenneth D. Tew and Nagahiro Saijo. Macmillan (UK). 6/yr. Europe $£ 125$, elsewhere $£ 135$.

PHARMACOLOGICAL research embraces a variety of disciplines from molecular biology to behavioural psychology. So, not surprisingly, there are many journals already devoted to the field, and one wonders whether there is any need for a new one. The editors and presumably the publishers of Cellular Pharmacology obviously think so.

In fact, the editors have addressed this question in a brief leading article in the opening issue. They believe that the journal will provide a niche for "work which is not directly defined by the review criteria of existing journals" and go on to say that "many existing journals return without review those papers that meld the disciplines of cellular biochemistry and pharmacology". For their sakes I hope they are correct.

There are, however, many specialist journals that already bridge this divide. Molecular Pharmacology, Biochemical Pharmacology and even more general pharmacology journals such as British Journal of Pharmacology publish papers based on research at a cellular level. So what is the novelty of this new journal? An obvious attraction के would be a short publishing time, which the editors attempt to keep to a minimum by requesting that papers be submitted on disk. Unfortunately, none of those published so far prints the date of submission or acceptance, so there is no indication of speed.

The papers are clearly typeset on good quality paper. The layout is comparable to other journals, although the figures, and particularly the captions, are variable. Articles consists of the usual sections; I fail to see the advantage of describing the methods and materials last, however.

The scope is wide drug mechanisms at the cellular level - and the editors intend eventually to run up-to-date reviews. On the whole, I did not find the articles (about eight per issue) particularly exciting, although one did catch my eye: "Interaction of new compounds at microtubular level" - the ultimate in imprecise titles. Reductionism in pharmacological research has become a major trend and, with this in mind, the journal may provide the extra publication space needed for the resulting flow of work.

N. G. Bowery is in the Department of Pharmacology, School of Pharmacy, University of London, 29-39 Brunswick Square, London WC1N $1 A X$, UK.

\section{Surface impression}

\section{Clare M. Isacke}

Epithelial Cell Biology. Editor Christopher S. Potten. Springer. 4/yr. 1120 (institutional).

SKIN, blood, bone, muscle, liver and many other parts of the body are honoured by their own specialist journals. Should the same be done for epithelial cells and tissues? In my opinion the answer is a definite yes. Workers in the field would benefit greatly from a forum that collects together the reviews, technical advances and original research papers currently scattered throughout an increasingly large number of other publications. Further, there is a genuine need for a journal that encourages papers on a variety of epithelia rather than just the model culture systems. This is undoubtedly a multidisciplinary and flourishing subject area, which produces an inherent problem for a new journal.

Epithelial Cell Biology neither covers a discrete enough subdiscipline to attract a select, specialist clientele, nor aims high enough to do what Neuron did for neurobiology: that is, compete for the topquality publications currently found in the main journals that cover cell biology, development and cancer. It is a journal struggling to maintain a middle ground. Although the quality and presentation of papers are good there are often long delays between their acceptance and publication, and charges are made for reproduction of colour plates.

For now, this slim journal will find it difficult to attract many individual subscribers, but libraries should be encouraged to add it to their racks. I hope it succeeds, although I fear that a firm editorial policy will be required if researchers are to be persuaded to submit their best papers.

Clare M. Isacke is in the Department of Biology, Imperial College of Science, Technology and Medicine, Prince Consort Road, London SW7 2BB, UK. 